\title{
Elaboration of an Easy Aqueous Sol-Gel Method for the Synthesis of Micro- and Mesoporous $\gamma-\mathrm{Al}_{2} \mathrm{O}_{3}$ Supports
}

\author{
Vincent Claude ${ }^{1}$, Hugo Solis Garcia ${ }^{2}$, Cédric Wolfs ${ }^{1}$, Stéphanie D. Lambert ${ }^{1}$ \\ ${ }^{1}$ Department of Chemical Engineering, University of Liege, Liege, Belgium \\ ${ }^{2}$ Chemical Engineering Faculty, Central University of Ecuador, Quito, Ecuador \\ Email: Stephanie.lambert@ulg.ac.be
}

How to cite this paper: Claude, V., Solis Garcia, H., Wolfs, C. and Lambert, S.D. (2017) Elaboration of an Easy Aqueous Sol-Gel Method for the Synthesis of Microand Mesoporous $\gamma-\mathrm{Al}_{2} \mathrm{O}_{3}$ Supports. $A d$ vances in Materials Physics and Chemistry, 7, 294-310.

https://doi.org/10.4236/ampc.2017.77023

Received: June 12, 2017

Accepted: July 22, 2017

Published: July 25, 2017

Copyright $\odot 2017$ by authors and Scientific Research Publishing Inc. This work is licensed under the Creative Commons Attribution International License (CC BY 4.0).

http://creativecommons.org/licenses/by/4.0/

\begin{abstract}
An aqueous sol-gel method for the synthesis of $\gamma-\mathrm{Al}_{2} \mathrm{O}_{3}$ supports has been developed for the use in tar reforming applications. It was determined the influences of two different aluminum precursors (aluminum sec-butoxide $\left(\mathrm{Al}\left[\mathrm{OCH}\left(\mathrm{CH}_{3}\right) \mathrm{CH}_{2} \mathrm{CH}_{3}\right]_{3}\right)$ and aluminum nitrate $\left.\left(\mathrm{Al}\left(\mathrm{NO}_{3}\right)_{3}\right)\right)$ on the textural and crystallographic properties of $\mathrm{Al}_{2} \mathrm{O}_{3}$ supports. Only the formation of $\gamma$ $\mathrm{Al}_{2} \mathrm{O}_{3}$ is aimed in order to use these alumina materials as catalytic supports, because it presents high specific surface area and pore volume values. Additionally, the synthesis of $\gamma-\mathrm{Al}_{2} \mathrm{O}_{3}$ was realized with the use of a functionalized silicon precursor, [3-(2-aminoethylamino)propyl]trimethoxysilane, called EDAS. By the presence of an ethylenediamine group in this molecule, it is possible to chelate metallic ions and to highly increase their dispersion at a molecular level during the synthesis of metallic catalysts supported on alumina, which is an asset for catalytic applications. So it was developed a synthesis sol-gel procedure for the cogelation between the functionalized silicon alkoxide EDAS and alumina precursor. The alumina supports synthesized with $\mathrm{Al}\left(\mathrm{NO}_{3}\right)_{3}$ as precursor presented higher porous values than the ones obtained with aluminium sec-butoxide precursor. Since nitrate salts are much easier to handle than alkoxides, these observations allowed validating $\mathrm{Al}\left(\mathrm{NO}_{3}\right)_{3}$ as aluminum source for the future synthesis procedures for metallic catalysts supported on alumina.
\end{abstract}

\section{Keywords}

Sol-Gel Process, $\gamma-\mathrm{Al}_{2} \mathrm{O}_{3}$ Supports, Aqueous Synthesis, Cogelation Method

\section{Introduction}

\subsection{The Sol-Gel Chemistry}

From several years, the sol-gel processes are developed for the synthesis of inor- 
ganic materials, and especially for metallic oxides with porous and tailored morphologies, and a homogeneous particle sizes distribution of crystallites $\left(\mathrm{SiO}_{2}, \mathrm{Al}_{2} \mathrm{O}_{3}, \mathrm{TiO}_{2}, \mathrm{ZrO}_{2}, \ldots\right)$ [1]. By definition, a sol is a colloidal suspension of solid particles $(1-1000 \mathrm{~nm})$ in a liquid, in which the dispersed phase is present in a low amount, and a gel is obtained by the cross-linking of the sol colloid and results in a solid network with a high liquid amount in its pores. In this way, a sol-gel process can simply be summarized as an inorganic polymerization realized in solution media [1]. The starting materials used for the sol-gel process can be various reagents such as metallic salts, metallic oxides, metallic hydroxides, metallic complexes or metallic alkoxides. They should be soluble in the reaction medium and reactive enough to participate in the gel forming process. Though offering many applications, the sol-gel processes can be divided into the following basic elementary steps: Solution formation, gelation, aging, drying and densification by final heat treatments [1].

Though being defined by the same synthesis steps, i.e. hydrolysis and condensation, depending on the type of precursors and solvent used, the sol-gel polymerization can be realized in two different paths: organic or aqueous. The organic paths are realized in organic solvents and use precursors sensitive to water, the most common ones being the metallic alkoxides. The polymerization is started when water is added to the mixture and occurs following Equations (1), (2) and (3) [1]:

First, an initial hydrolysis step, where the alkoxide precursor reacts with water:

$$
\mathrm{M}-\mathrm{OR}+\mathrm{H}_{2} \mathrm{O} \rightarrow \mathrm{M}-\mathrm{OH}+\mathrm{R}-\mathrm{OH}
$$

where $\mathrm{M}$ is a metal and $\mathrm{R}$ is an alkyl group. After, the inorganic network is formed via the condensation step. The hydroxyl group reacts with another hydroxyl group to form water:

$$
\mathrm{M}-\mathrm{OH}+\mathrm{M}-\mathrm{OH} \rightarrow \mathrm{M}-\mathrm{O}-\mathrm{M}+\mathrm{H}_{2} \mathrm{O}
$$

or with an initial precursor to form alcohol:

$$
\mathrm{M}-\mathrm{OR}+\mathrm{M}-\mathrm{OH} \rightarrow \mathrm{M}-\mathrm{O}-\mathrm{M}+\mathrm{R}-\mathrm{OH}
$$

Numerous studies have shown that it is possible to influence the hydrolysis and condensation rates through the control of various experimental parameters (temperature, $\mathrm{pH}, \mathrm{H}_{2} \mathrm{O} /$ solvent ratio, agitation time) [1] [2] [3] [4]. A gel obtained with a very fast hydrolysis (Equation (1)) will consist of small particles, which are highly reticulated, whereas a slower hydrolysis will present larger grains, with less interconnections.

In aqueous paths, after the solubilization of metallic cations in water, complexes such as aquo- $\left(\left[\mathrm{M}\left(\mathrm{OH}_{2}\right)_{\mathrm{n}}\right]^{\mathrm{z}+}\right)$, hydroxo- $\left(\left[\mathrm{M}(\mathrm{OH})_{\mathrm{n}}\right]^{(\mathrm{n}-\mathrm{z})-}\right)$ or oxo- $\left(\left[\mathrm{M}(\mathrm{O})_{\mathrm{n}}\right]^{(2 \mathrm{n}-\mathrm{z})-}\right)$ compounds, with $2<\mathrm{n}<8$ and $1<\mathrm{z}<7$ are formed [5]. These complexes combine with two different condensation mechanisms: the olation and the oxolation [5]. The olation reaction occurs between complexes composed of hydroxo$(-\mathrm{OH})$ and aquo- $\left(-\mathrm{OH}_{2}\right)$ groups as follows (Equation (4)): 


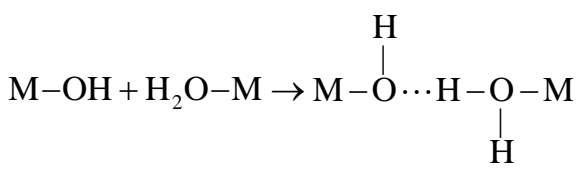

Thereafter, the $\mathrm{M}-\mathrm{OH}_{2}$ bond is broken, a hydroxo-bridge $\mathrm{M}-\mathrm{OH}-\mathrm{M}$ is formed and the ligand $\mathrm{H}_{2} \mathrm{O}$ is eliminated (Equation (5)):

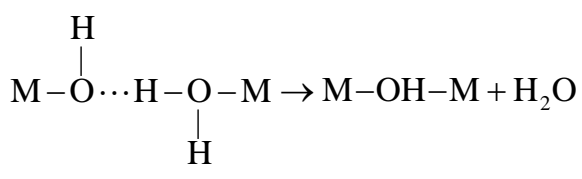

The bridging $-\mathrm{OH}$ ligands are called "ol" in order to differentiate them from hydroxo-ligands at the extremity. So the "olation" is the reaction leading to the formation of an "ol" bridge (-OH-) between two metals. Olation reactions are generally fast and depend mainly on the lability, i.e. the ability of bond cleavage, of the $\mathrm{M}-\mathrm{OH}_{2}$ bond. The lability of the $\mathrm{M}-\mathrm{OH}_{2}$ bond depends on the polarization of the cation: the bond is more inclined to be broken for cations with low charge $\mathrm{z}$ or for large cations. The olation reaction is supposed to occur according to a nucleophilic substitution of type SN1 (the reaction rate is of first-order and depends only on the electrophile) [5]. The second condensation mechanism is called "oxolation". It occurs when both precursors do not contain any aquo ligands $\left(-\mathrm{OH}_{2}\right)$ coordinated to the metallic cation. It involves the condensation of two hydroxo (-OH) groups to form $\mathrm{H}_{2} \mathrm{O}$ as follows (Equation (6)):

First, a nucleophilic addition with formation of an "-ol" bridge leads to an unstable transition state:

$$
\mathrm{M}-\stackrel{\delta^{-}}{\mathrm{O}}+\stackrel{\delta^{+}}{\mathrm{M}}-\stackrel{\delta^{-}}{\mathrm{OH}} \rightarrow \stackrel{\delta^{+}}{\mathrm{M}}-\stackrel{\mathrm{H}}{\mathrm{O}}-\mathrm{M}-\stackrel{\delta^{-}}{\mathrm{O}}-\mathrm{H}
$$

Thereafter, a proton is transferred to a terminal $-\mathrm{OH}$ ligand to form an aquogroup, which is finally eliminated (Equation (7)):

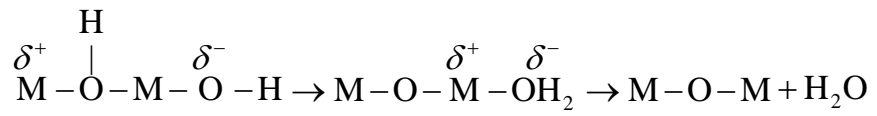

Condensation mechanisms by oxolation lead to the formation of "-oxo" $(-\mathrm{O}-)$ bridges. However, contrary to olation reactions, oxolation reactions are usually influenced by the acidity of the solution and are slower [5]. The oxolation reaction is supposed to occur according to a nucleophilic substitution of type SN2 (the reaction rate is of second-order and depends on both reagents). Two essential conditions are required for the oxolation reaction to take place: 1$)$ the presence of a hydroxo- $(-\mathrm{OH})$ ligand carrying a negative charge $(\delta(\mathrm{OH})<0)$ in the coordination sphere of a cation; 2 ) the possibility of a cation to undergo the nucleophilic attack from a hydroxo-ligand, i.e. the cation must be sufficiently electrophile to undergo the attack $(\delta(\mathrm{M})>+0.3)$ [5].

\subsection{Types of Aluminum Hydroxides and Calcined Alumina}

The comparison of aqueous and organic paths for the synthesis of $\gamma-\mathrm{Al}_{2} \mathrm{O}_{3}$ was 
studied by Rajaeiyan et al. [6]. The authors showed that after a classic calcination under air at $T=750^{\circ} \mathrm{C}$, more interesting structural and textural properties were obtained for the aqueous method compared to the organic path. Indeed, the specific surface area of alumina synthesized with aqueous path is higher $\left(200 \mathrm{~m}^{2} / \mathrm{g}\right)$ compared to alumina synthesized with organic path $\left(30 \mathrm{~m}^{2} / \mathrm{g}\right)$. Furthermore, $\gamma-\mathrm{Al}_{2} \mathrm{O}_{3}$ peaks are visible on XRD spectrum for the sample synthesized with the aqueous method, whereas the sample synthesized with the organic method shows amorphous alumina peaks.

When dissolved into water, the aluminum ions can form different complexes depending on the $\mathrm{pH}$ value: $\mathrm{Al}_{3}(\mathrm{OH})_{4}^{5+}$ for $\mathrm{pH}<1, \mathrm{Al}^{3+}$ for $1<\mathrm{pH}<4$, $\mathrm{Al}(\mathrm{OH})_{2}^{+}$for $4<\mathrm{pH}<6, \mathrm{Al}(\mathrm{OH})_{3}$ for $5<\mathrm{pH}<8$ and $\mathrm{Al}(\mathrm{OH})_{4}^{-}$for $\mathrm{pH}>7.5$ [7]. Once formed, these aqueous complexes will condense and form cross-linking networks via oxolation and olation reactions previously described. The final material properties (crystallinity, specific surface area and pore volume) depend strongly on the experimental conditions such as the temperature, the type of precursors, the agitation or the aging conditions. So depending on these synthesis conditions, the basic brick of aluminum hydroxide $\left(\mathrm{Al}(\mathrm{OH})_{3}\right)$ can either be aggregated into amorphous alumina hydroxide $\left(\mathrm{Al}(\mathrm{OH})_{3}\right)$, diaspore $(\alpha$-AlOOH $)$ or boehmite $(\gamma$-AlOOH). Therefore, controlling the formation of these different compounds is of major relevance. Indeed, after a classic calcination under air at $T=500^{\circ} \mathrm{C}, \mathrm{Al}(\mathrm{OH})_{3}$ leads to $\eta-\mathrm{Al}_{2} \mathrm{O}_{3}$, whereas diaspore leads to $\alpha-\mathrm{Al}_{2} \mathrm{O}_{3}$ and only boehmite leads to $\gamma-\mathrm{Al}_{2} \mathrm{O}_{3}$ [5] [7] [8].

Okada et al. [9] emphasized the importance of the operating variables: the formation of boehmite under atmospheric pressure is guaranteed only for temperatures from $70^{\circ} \mathrm{C}$ to $100^{\circ} \mathrm{C}$, and for $\mathrm{pH}$ values comprised between 7.5 and 10 . Indeed, under these aging conditions, the amorphous aluminum hydroxide and diaspore crystals formed during the precipitation are inclined to undergo dissolution/reprecipitation mechanisms to form $\left[\mathrm{Al}(\mathrm{OH})_{4}\right]^{-}$complexes, which are rearranged to form the boehmite phase. This phenomenon was confirmed by Lee et al. [10], showing that by allowing the formation of $\gamma$-AlOOH, these conditions allow obtaining after calcination very porous alumina materials with the highest specific surface area and pore volume.

\subsection{The Cogelation Method}

The cogelation method allows the synthesis of homogenous supports from the hydrolysis and condensation of different kind of precursors. For example for the formation of $\mathrm{SiO}_{2}$, two alkoxides of the same element are used: tetramethoxysilane (TMOS; $\left.\mathrm{Si}\left(\mathrm{OCH}_{3}\right)_{4}\right)$ and tetraethoxysilane (TEOS; $\left.\mathrm{Si}\left(\mathrm{OC}_{2} \mathrm{H}_{5}\right)_{4}\right)$ [1]. It is also possible to start from one alkoxide and one salt, for example the synthesis of $\mathrm{Al}_{2} \mathrm{O}_{3}$ with a mixture of aluminum isopropoxide $\left(\mathrm{Al}\left(\mathrm{OC}_{3} \mathrm{H}_{7}\right)_{3}\right)$ and aluminum nitrate $\left(\mathrm{Al}\left(\mathrm{NO}_{3}\right)_{3}\right)[11]$, or $\mathrm{Al}\left(\mathrm{OC}_{3} \mathrm{H}_{7}\right)_{3}$ and aluminum acetylacetonate $\left(\mathrm{Al}\left(\mathrm{C}_{5} \mathrm{H}_{7} \mathrm{O}_{2}\right)_{3}\right)$ [12]. For the synthesis of zeolithes, the cogelation method is used with two alkoxides with two different elements: TEOS and aluminum isopro- 
poxide, or TEOS and aluminum sec-butoxide [13].

Cogelation with a functionalized precursor is also possible in order to highly disperse metallic active sites inside inorganic support. For example, the use of silicon alkoxide containing a functional organic group like ethylenediamine, which is able to form a chelate with a metallic cation, showed to be an innovative and efficient way to improve the performances of catalytic materials. In this way, Lambert et al. synthesized finely dispersed $\mathrm{Pd} / \mathrm{SiO}_{2}$ [14] [15], $\mathrm{Ag} / \mathrm{SiO}_{2}$ [15], $\mathrm{Cu} / \mathrm{SiO}_{2}$ [15] [16], $\mathrm{Ni} / \mathrm{SiO}_{2}$ [17], $\mathrm{Pd}-\mathrm{Ag} / \mathrm{SiO}_{2}$ [18] [19], $\mathrm{Pd}-\mathrm{Cu} / \mathrm{SiO}_{2}$ [19], Ni$\mathrm{Cu} / \mathrm{SiO}_{2}$ [17] and $\mathrm{Fe}_{2} \mathrm{O}_{3} / \mathrm{SiO}_{2}$ [20] catalysts by the cogelation between TEOS and a silicon alkoxide functionalized with a ethylenediamine group (3-(2-aminoethylamino)propyltrimethoxysilane, $\left(\mathrm{CH}_{3} \mathrm{O}\right)_{3}-\mathrm{Si}-\left(\mathrm{CH}_{2}\right)_{3}-\mathrm{NH}-\left(\mathrm{CH}_{2}\right)_{2}-\mathrm{NH}_{2}$, called EDAS).

Since no functionalized aluminum alkoxides are commercially available, the functionalization of alumina supports is nowadays only performed via grafting methods [21] [22] [23]. The usual methods consist in the mixing of a functionalized silica precursor with an alumina support in an organic solvent. Thereafter, a small quantity of water is added to hydrolyze the alkoxy groups and form silanol groups, which graft onto the alumina support by condensation reactions. Nevertheless, these methods are nevertheless not convenient and difficult to scale up, principally because of the required synthesis conditions (inert and dry atmosphere, toxic organic solvents). The purpose of this work is to perform the synthesis of very porous $\gamma-\mathrm{Al}_{2} \mathrm{O}_{3}$ supports modified by EDAS molecules thanks to a simple and classic aqueous cogelation method.

\section{Experimental Procedure}

\subsection{Sample Preparation}

Two synthesis methods were used for the synthesis of $\gamma-\mathrm{Al}_{2} \mathrm{O}_{3}$ and EDAS modified $\gamma-\mathrm{Al}_{2} \mathrm{O}_{3}$ supports. The first method, called method A (related to "alkoxide"), used aluminum sec-butoxide $\left(\mathrm{Al}\left[\mathrm{OCH}\left(\mathrm{CH}_{3}\right) \mathrm{CH}_{2} \mathrm{CH}_{3}\right]_{3}\right)$ as aluminum source. The second one, called method $\mathrm{N}$ (related to "nitrate"), used aluminum nitrate $\left(\mathrm{Al}\left(\mathrm{NO}_{3}\right)_{3}\right)$ as aluminum source. For both methods, the reagents were dissolved in a media solution with $\mathrm{H}_{2} \mathrm{O} /(\mathrm{Al}+3 / 4 \mathrm{Si})$ and Ethanol/( $\left.\mathrm{Al}+\mathrm{Si}\right)$ molar ratios equal to 50 and 5 respectively. The presence of the fraction $3 / 4$ in the first ratio was justified by the fact that only the three methoxy groups in the EDAS molecule are hydrolyzed by water. Ethanol was added to the media solution in order to prevent a direct contact of EDAS with $\mathrm{H}_{2} \mathrm{O}$, which is known to lead to macroscopic silicate aggregates [1]. The different amounts of reagent ( $\mathrm{Al}$ secbutoxide, Al nitrate, EDAS, water, ethanol) used for the synthesis of $10 \mathrm{~g}$ of calcined material are presented in Table 1.

This procedure was developed for the synthesis of catalytic supports doped with $2 \mathrm{wt} . \%$ of $\mathrm{Ni}$ (not presented in this paper). Therefore, the amount of EDAS was calculated in order to chelate all nickel ions, i.e. the Ni/EDAS ratio is equal to 4 . 
Table 1. Synthesis operating variables of $\gamma-\mathrm{Al}_{2} \mathrm{O}_{3}$ and EDAS modified $\gamma-\mathrm{Al}_{2} \mathrm{O}_{3}$ supports.

\begin{tabular}{ccccc}
\hline Sample & $n_{\mathrm{Al}}{ }^{a}(\mathrm{~mol})$ & $n_{\mathrm{EDAS}}(\mathrm{mol})$ & $n_{\mathrm{H}_{2} \mathrm{O}}(\mathrm{mol})$ & $n_{\mathrm{C}_{2} \mathrm{H}_{5} \mathrm{OH}}(\mathrm{mol})$ \\
\hline $\mathrm{A}$ & 0.196 & 0 & 170 & 60 \\
A-EDAS & 0.180 & 0.014 & 170 & 60 \\
$\mathrm{~N}$ & 0.196 & 0 & 170 & 60 \\
N-EDAS & 0.180 & 0.014 & 170 & 60 \\
\hline
\end{tabular}

${ }^{\mathrm{a}} n_{\mathrm{Al}}$, the aluminum precursor, is $\mathrm{Al}$ sec-butoxide in samples $\mathrm{A}$ and $\mathrm{Al}$ nitrate in samples $\mathrm{N}$.

The preparation of samples $\mathrm{A}$ and A-EDAS was realized as follows: $\mathrm{Al}$ sec-butoxide was quickly $(1 \mathrm{~mL} / \mathrm{s})$ injected into the solution (water + ethanol) under vigorous stirring. The sol was then stirred for $30 \mathrm{~min}$. The variant method consisted in adding EDAS to the solution (water + ethanol) under vigorous stirring $(500 \mathrm{rpm}$ ) for $5 \mathrm{~min}$ before adding $\mathrm{Al} \mathrm{sec}$-butoxide. After the stirring, the $\mathrm{pH}$ value was increased to 9.5 by a dropwise $(1 \mathrm{~mL} / \mathrm{min})$ addition of a $\mathrm{NH}_{3}$ aqueous solution (15 M).

The preparation of samples $\mathrm{N}$ and N-EDAS was realized as follows: $\mathrm{Al}\left(\mathrm{NO}_{3}\right)_{3}$ was dissolved in the solution (water + ethanol) and the sol was then stirred for $30 \mathrm{~min}$. The variant method consisted in adding EDAS to the solution under vigorous stirring for $5 \mathrm{~min}$ before adding $\mathrm{Al}\left(\mathrm{NO}_{3}\right)_{3}$. The rest of the procedure is similar to the preparation of samples A and A-EDAS.

For both methods, after increasing the $\mathrm{pH}$ value until 9.5, the vessels were closed and the solutions were mixed under vigorous stirring in a heated oil bath at $85^{\circ} \mathrm{C}$ for $24 \mathrm{~h}$. After the agitation step, the vessels were opened and put into an oven at $85^{\circ} \mathrm{C}$ for aging for $24 \mathrm{~h}$ with a pressure equal to $700 \mathrm{mbar}$. The obtained gels were washed twice with water and once with ethanol. Thereafter, the washed gels were put into an oven at $110^{\circ} \mathrm{C}$ for drying for $24 \mathrm{~h}$ with a pressure equal to $900 \mathrm{mbar}$. The dried samples were calcined under air for $4 \mathrm{~h}$ at $T=500^{\circ} \mathrm{C}$ with a heating rate equal to $2^{\circ} \mathrm{C} / \mathrm{min}$.

\subsection{Sample Characterization}

TG-DSC measurements were performed on a SensysSetaram instrument. $0.05 \mathrm{~g}$ of the samples were crushed and introduced into an alumina crucible. The samples were heated from $25^{\circ} \mathrm{C}$ to $800^{\circ} \mathrm{C}$ with a heating rate of $2^{\circ} \mathrm{C} / \mathrm{min}$ under air (20 $\mathrm{mL} / \mathrm{min})$.

Apparent densities were measured by helium pycnometry with a Micromeritics AccuPyc 1330 at $T=25^{\circ} \mathrm{C}$. Mercury porosimetry measurements were performed with $0.3 \mathrm{~g}$ of sample using a Poremaster 60 instrument from Quantachrome with pressures going from 1 to 40.000 bars. Nitrogen adsorption-desorption isotherms were measured at $-196^{\circ} \mathrm{C}$ on a Micromeritics ASAP 2010 instrument after $12 \mathrm{~h}$ of outgassing at $300^{\circ} \mathrm{C}$ and $10^{-5} \mathrm{mbar}$.

SEM measurements were performed with a FEI ESEM-FEG XL3 device. Pictures made with Backscattered Electrons (SEM-BSE) detectors permitted to get a view of the surface of the samples, with different contrasts depending on the 
elemental composition. Energy Dispersive X-ray analyses (SEM-EDX) were also performed with the same apparatus in order to determine the elemental composition of a defined a surface $\left(400 \times 300 \mu \mathrm{m}^{2}\right)$ and to build up element mapping pictures. The measurements were performed at an acceleration voltage of 15 $\mathrm{keV}$, set on the Spot 4 and with a vacuum of 0.4 Torr.

TEM analyses were performed on a CM10-PW6020 Philips Electron Microscope. First, crushed samples were dispersed in absolute ethanol. Then a drop of the dispersion was placed on a copper grid (Formvar/Carbon $200 \mathrm{Mesh} \mathrm{Cu}$ from Agar Scientific). For a higher quality of the pictures, the vacuum lines were cooled with liquid nitrogen for 30 min before the measurements.

X-ray diffraction measurements were performed on a Bruker D8 Twin-Twin diffractometer ( $\mathrm{Cu}-\mathrm{K}_{\alpha}$ Radiation). The samples were crushed and the measurements were performed from $2 \theta=30^{\circ}$ to $2 \theta=80^{\circ}$ with a step time of $18 \mathrm{~s}$ and a step size of $0.04 \mathrm{~s}$. The sizes of alumina crystallites were calculated by using the Scherrer equation centered on the $\left(\begin{array}{lll}4 & 0 & 0\end{array}\right)$ peak of $\gamma-\mathrm{Al}_{2} \mathrm{O}_{3}\left(2 \theta=67.0^{\circ}\right)$ of the XRD spectra [24].

\section{Results}

Figure 1 presents the $\mathrm{pH}$-curves of samples A, A-EDAS, N and N-EDAS.

The samples precipitated with Al sec-butoxide (samples A and A-EDAS) require minimal $\mathrm{NH}_{3}$ additions (around $1 \mathrm{~mL}$ ) in order to reach a $\mathrm{pH}$ value of 9.5. In contrary, the samples synthesized with $\mathrm{Al}\left(\mathrm{NO}_{3}\right)_{3}$ (samples $\mathrm{N}$ and $\mathrm{N}$-EDAS) present very similar $\mathrm{pH}$-curves typical for aqueous alumina synthesis with a base and are characterized by three distinct fields [25]:

1) for volumes $<15 \mathrm{~mL}$, i.e. $\mathrm{pH}<4$, the titration curves are almost horizontal, which indicates that the polymerization rate of the very small $\mathrm{Al}$ aggregates is fast and continuous. Mononuclear $\mathrm{Al}$ complexes condensed to form $\mathrm{Al}_{2}-\mathrm{Al}_{12}$ species such as $\mathrm{Al}_{2}(\mathrm{OH})_{4}^{2+}, \mathrm{Al}_{6}(\mathrm{OH})_{12}^{6+}$ and $\mathrm{Al}_{10}(\mathrm{OH})_{22}^{8+}$;

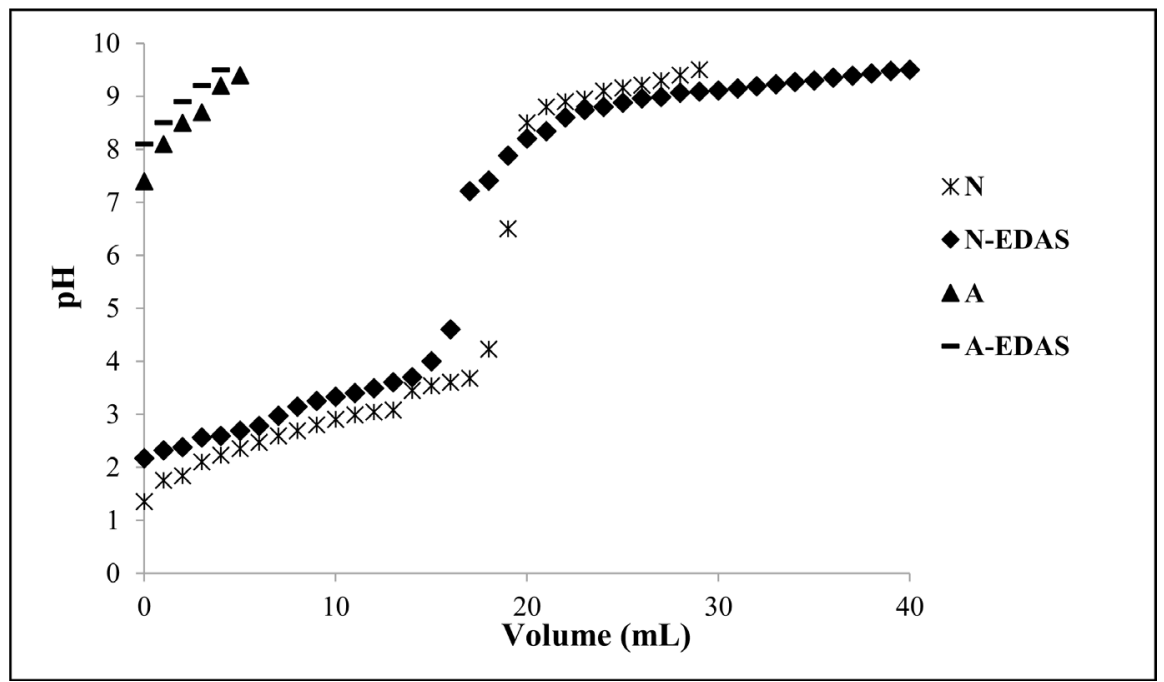

Figure 1. $p H$-curves for samples A, A-EDAS, $\mathrm{N}$ and $\mathrm{N}$-EDAS. 
2) for $15 \mathrm{~mL}<$ volumes $<22 \mathrm{~mL}$, i.e. $4<\mathrm{pH}<7$, the main $\mathrm{Al}$ species are larger polymers $\left(\mathrm{Al}_{13}-\mathrm{Al}_{54}\right)$. In this field, the rate of polymerization is very slow, thus an addition of $\mathrm{OH}$-ions strongly raises the $\mathrm{pH}$ value;

3) for volumes $>22 \mathrm{~mL}$, i.e. $\mathrm{pH}>9$, most of the $\mathrm{Al}$ species are converted in crystalline boehmite AlOOH.

Though presenting similar shapes, it is observed slight differences between the $\mathrm{N}$ and $\mathrm{N}$-EDAS $\mathrm{pH}$-curves. Indeed, the initial $\mathrm{pH}$ value is higher for sample N-EDAS: at $V_{\mathrm{NH}_{3}}=0 \mathrm{~mL}, \mathrm{pH}_{\mathrm{N} \text {-EDAS }}=2.2$, whereas $\mathrm{pH}_{\mathrm{N}}=1.3$. This difference of $\mathrm{pH}$ is due to the intrinsic basic properties of the amino groups of EDAS molecules [26]. Consequently, sample N-EDAS enters in the second field of $\mathrm{pH}$-curve at a lower $\mathrm{NH}_{3}$ volume addition compared to sample $\mathrm{N}\left(V_{\mathrm{NH}_{3}}=14 \mathrm{~mL}\right.$ for sample N-EDAS, whereas $V_{\mathrm{NH}_{3}}=17 \mathrm{~mL}$ for sample $\mathrm{N}$ ). However, the third field of $\mathrm{pH}$-curve for sample $\mathrm{N}$-EDAS8 is much longer compared to sample $\mathrm{N}$, thus resulting in a higher total $\mathrm{NH}_{3}$ volume needed for sample $\mathrm{N}$-EDAS to reach a $\mathrm{pH}$ value of 9.5 (29 $\mathrm{mL}$ for sample $\mathrm{N}$ and $40 \mathrm{~mL}$ for sample $\mathrm{N}$-EDAS).

TG-DSC measurements are performed on dried gels in order to understand the thermal behaviors of the materials (Figure 2).

The samples made of raw alumina (samples A and N, Figure 2(a) and Figure 2(b)) present similar TG-DSC curves, i.e. a first endothermic peak at about $100^{\circ} \mathrm{C}$, which corresponds to the evaporation of water, followed by a second peak located between $250^{\circ} \mathrm{C}$ and $500^{\circ} \mathrm{C}$, which corresponds to the transformation of boehmite into $\gamma-\mathrm{Al}_{2} \mathrm{O}_{3}$ [27] [28]. This second peak is more pronounced for sample $\mathrm{N}$ than for sample A. From $500^{\circ} \mathrm{C}$ to $800^{\circ} \mathrm{C}$, the evacuation of hydroxyl groups retained in the alumina network is evidenced by a slow and constant increase of the DSC curves associated with a slow decrease of the TG curves [28]. In Figure 2(c) and Figure 2(d), EDAS doped alumina (samples A-EDAS and N-EDAS) are characterized by an additional weight loss of about 10 wt.\% associated with a high exothermic peak situated between $210^{\circ} \mathrm{C}$ and $220^{\circ} \mathrm{C}$, which is caused by the degradation of the organic compounds of EDAS.

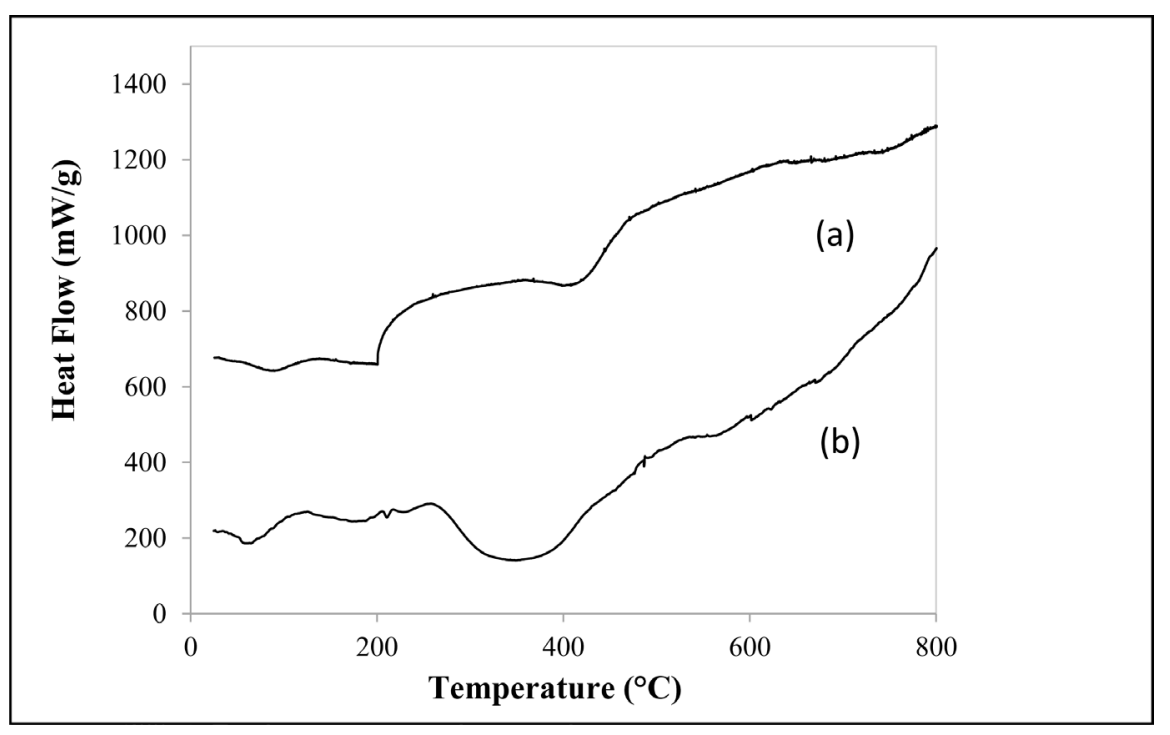




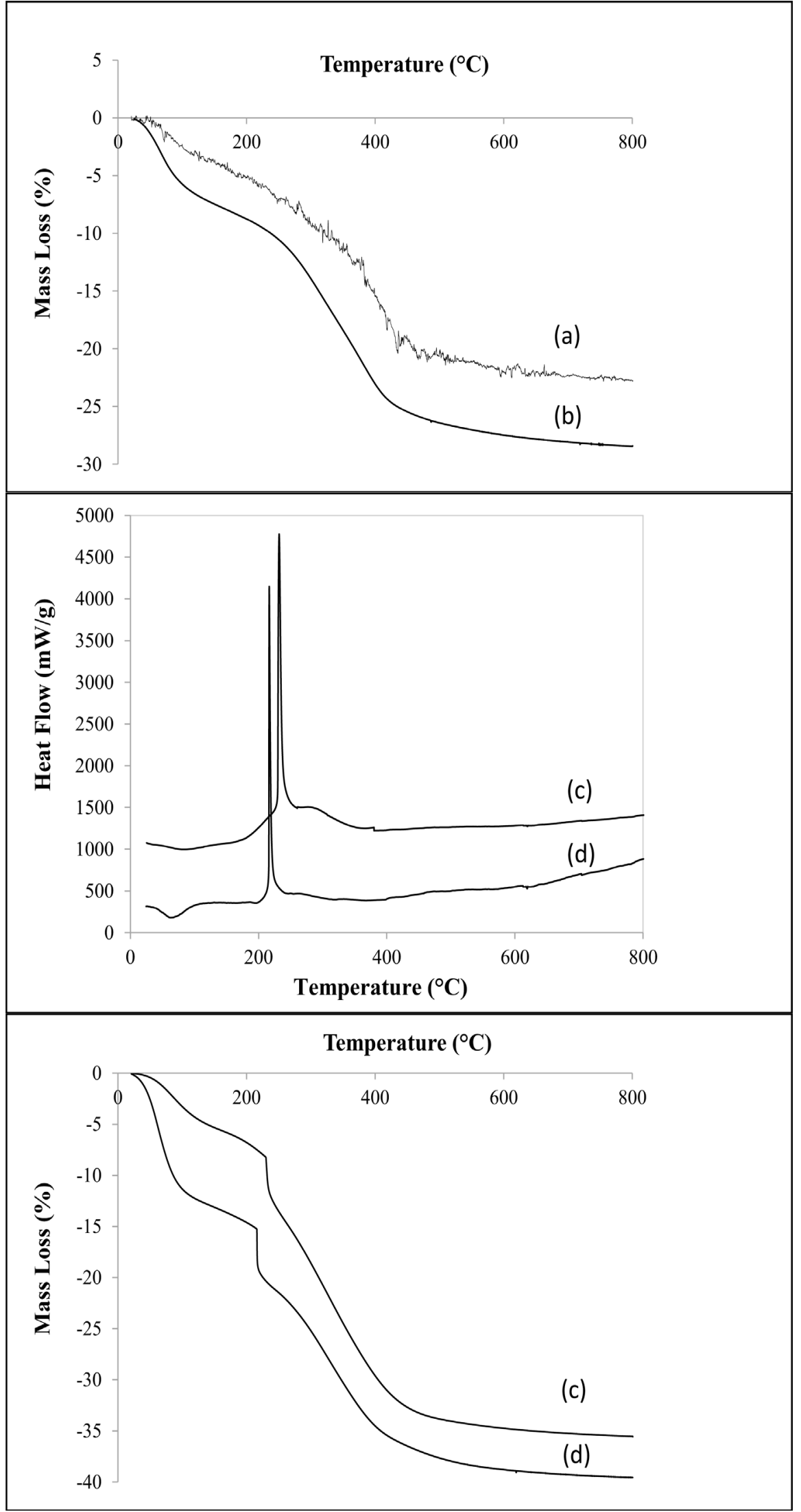

Figure 2. TG-DSC curves of samples: (a) A, (b) N, (c) A-EDAS, (d) N-EDAS. 
Figure 3 shows SEM-BSE pictures of calcined samples. The samples present similar microscopic surface aspects, composed of aggregates of alumina micrograins with sizes between 0.5 and $10 \mu \mathrm{m}$. Though the surfaces of samples are rough, all the grains are dense and show no macroporosity. Indeed, the macroporous volume, $V_{\mathrm{Hg}}$, calculated from mercury porosimetry measurements are below $0.1 \mathrm{~cm}^{3} / \mathrm{g}$ for all the samples. SEM-EDX mapping measurements are realized on sample N-EDAS and confirm the homogeneity of the samples at microscale (Figure 4).

Figure 5 shows TEM micrographs of the calcined samples.

The samples made of pure alumina (samples A and N) present platelet-like crystallites assembled in a random way, which is apparently characteristic for $\gamma-\mathrm{Al}_{2} \mathrm{O}_{3}$ supports synthesized by sol-gel methods [6]. EDAS modified alumina (samples A-EDAS and N-EDAS) present small elliptical crystallites assembled in a dense and compact network.

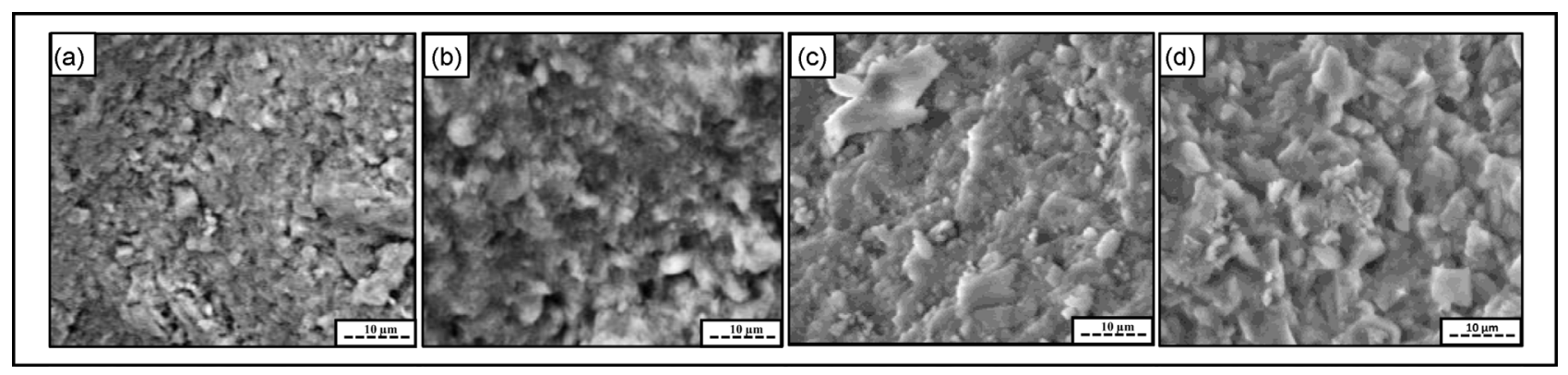

Figure 3. SEM pictures of calcined samples: (a) A, (b) A-EDAS, (c) N, (d) N-EDAS. Analysis conditions: 15 kV, $2000 \times$.

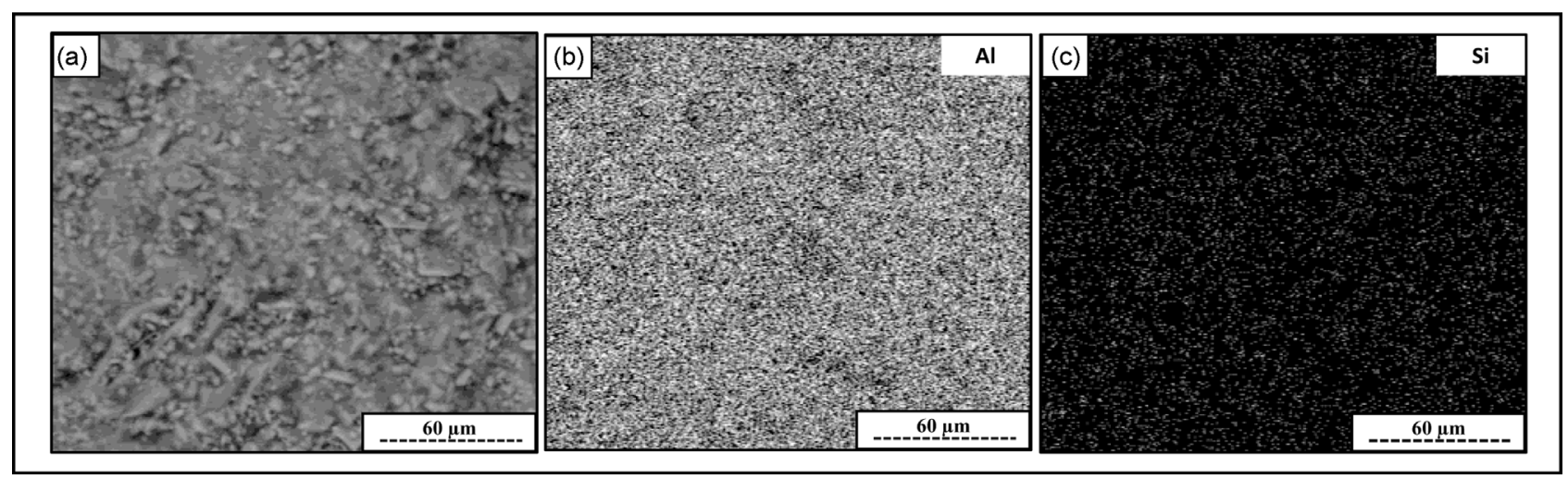

Figure 4. $\mathrm{Al}$ and $\mathrm{Si}$ element mapping of calcined sample N-EDAS. Analysis condition: $15 \mathrm{kV}, 400 \times$.

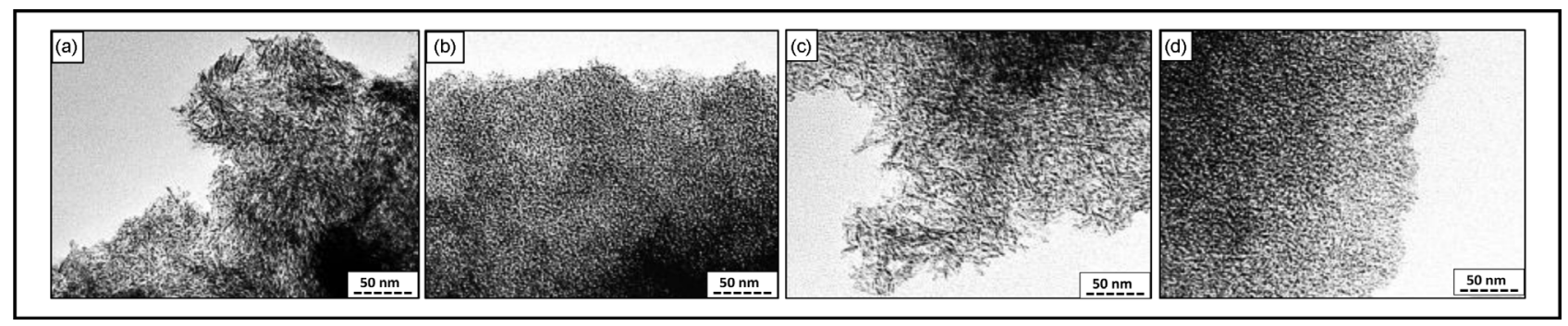

Figure 5. TEM pictures of calcined samples: (a) A, (b) A-EDAS, (c) N, (d) N-EDAS; 245.000×. 
Table 2 lists the textural and crystallographic properties of the calcined samples obtained from the nitrogen adsorption-desorption isotherms ( $S_{\mathrm{BET}}, V_{\mathrm{p}}, S_{\text {meso }}$, $\left.V_{\text {Dubinin }}\right)$, X-Ray diffraction $\left(d_{\mathrm{XRD}}\right)$ and helium pycnometry analyses $(\rho)$.

The nitrogen adsorption-desorption isotherms and their respective pore size distributions are shown in Figure 6.

All isotherms are characterized by: 1$)$ at low relative pressure $\left(p / p_{0}\right)$, a sharp increase of the adsorbed volume followed by a plateau, which corresponds to a

Table 2. Sample textural properties and alumina particle size.

\begin{tabular}{ccccccc}
\hline Sample & $S_{\text {BET }}\left(\mathrm{m}^{2} / \mathrm{g}\right)$ & $V_{\mathrm{p}}\left(\mathrm{cm}^{3} / \mathrm{g}\right)$ & $S_{\text {meso }}\left(\mathrm{m}^{2} / \mathrm{g}\right)$ & $V_{\text {Dubinin }}\left(\mathrm{cm}^{3} / \mathrm{g}\right)$ & $\rho\left(\mathrm{g} / \mathrm{cm}^{3}\right)$ & $d_{\text {XRD }}(\mathrm{nm})$ \\
\hline $\mathrm{A}$ & 230 & 0.50 & 195 & 0.09 & 3.15 & 4.5 \\
A-EDAS & 395 & 0.35 & 200 & 0.13 & 2.73 & 3.5 \\
$\mathrm{~N}$ & 340 & 0.60 & 280 & 0.12 & 2.97 & 4.5 \\
N-EDAS & 530 & 0.30 & 225 & 0.17 & 2.84 & 3.5 \\
\hline
\end{tabular}

$S_{\text {BET }}$ : specific surface area obtained by the BET method; $V_{\mathrm{p}}$ : specific liquid volume adsorbed at saturation pressure of nitrogen; $S_{\text {meso }}$ : specific surface area of mesopores determined by Broekhoff-de-Boer theory; $V_{\text {Dubinin }}$ : microporous volume determined by Dubinin-Raduskevich theory; $\rho$ : apparent density measured by helium pycnometry; $d_{\mathrm{XRD}}$ : alumina particle size determined from XRD measurements.

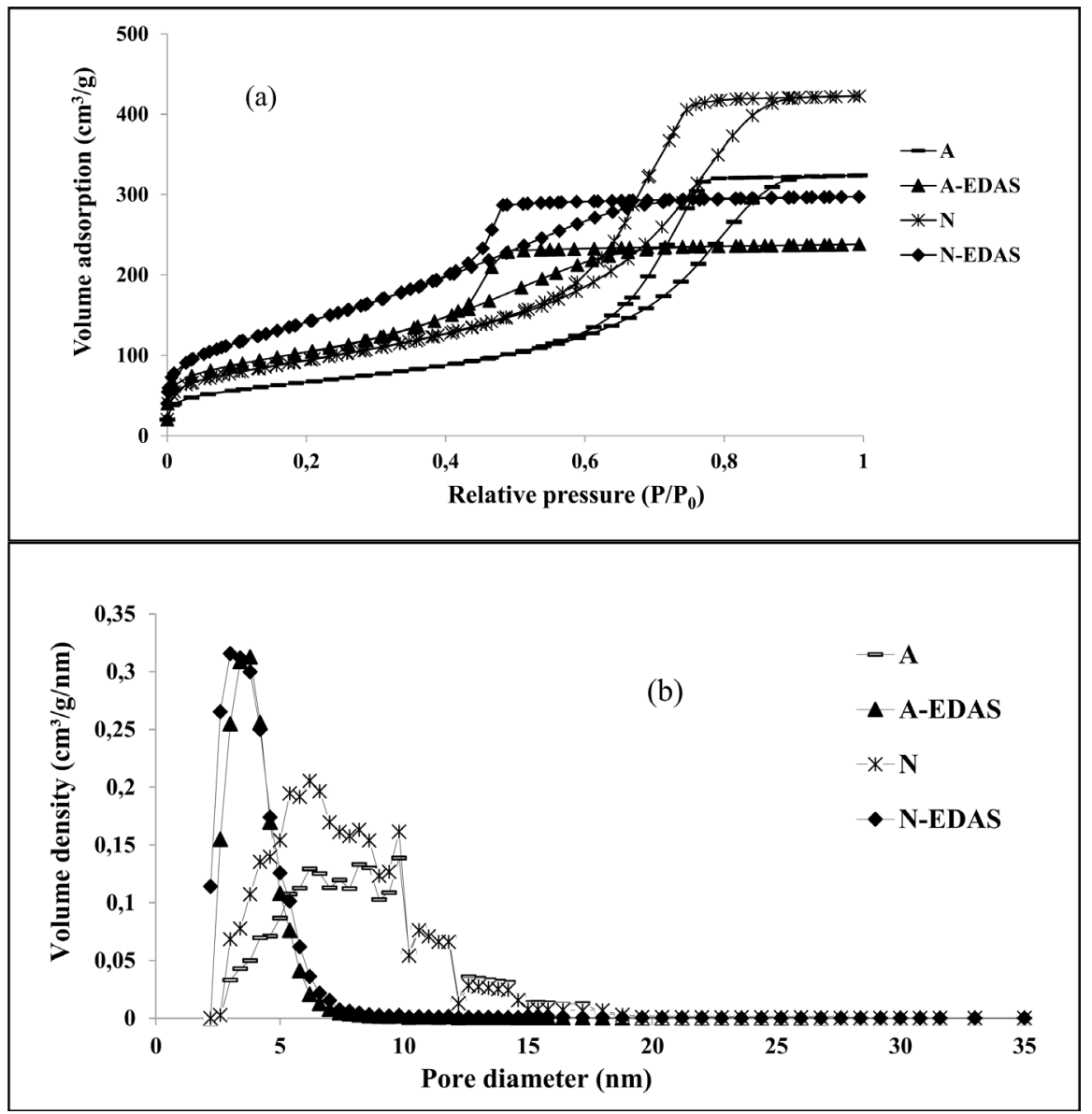

Figure 6. Nitrogen adsorption-desorption curves (a) and mesopore size distribution (b) of calcined samples A, A-EDAS, N and N-EDAS. 
type I isotherm according to BDDT classification, is characteristic of microporous adsorbents. Furthermore, the microporous volume, $V_{\text {Dubinin }}$, is important for all samples $\left.\left(>0.05 \mathrm{~cm}^{3} / \mathrm{g}\right) ; 2\right)$ at higher pressure $\left(p / p_{0}>0.4\right)$, the samples exhibit a broad hysteresis, which is characteristic of a nitrogen adsorption-desorption type IV isotherm according to the BDDT classification; 3) a high pore volume, $V_{\mathrm{p}}$ [15] [16] [17] [18] [19]. All the samples present a mesoporous pore size distribution comprised between 2 and $30 \mathrm{~nm}$.

Despite showing nitrogen adsorption-desorption isotherms and pore size distributions with similar shapes, it is observed that sample $\mathrm{N}$ is more porous than sample A $\left(+48 \%\right.$ for $S_{\mathrm{BET}},+20 \%$ for $V_{\mathrm{p}},+44 \%$ for $S_{\text {meso }},+33 \%$ for $V_{\text {Dubinin }}$, Table 2$)$.

In corroboration with TEM observations, it is observed that the addition of EDAS modifies the pore size distribution of both samples A-EDAS and N-EDAS in a similar way (Figure 6, Table 2). Indeed, both samples present an isotherm hysteresis shifted to a lower $p / p_{0}$ value, a higher specific surface area $(+72 \%$ for $S_{\mathrm{BET}}$ for sample A-EDAS and $+56 \%$ for $S_{\mathrm{BET}}$ for sample N-EDAS), a lower total porous volume and a notable microporous volume increase $\left(-30 \%\right.$ for $V_{\mathrm{p}}$ and $+44 \%$ for $V_{\text {Dubinin }}$ for sample A-EDAS; $-50 \%$ for $V_{\mathrm{p}}$ and $+42 \%$ for $V_{\text {Dubinin }}$ for sample N-EDAS) in comparison with the respective pure alumina samples A and N. In presence of EDAS, the influences of the nature of the aluminum precursor are the following: higher specific surface area and higher microporous volume values for sample N-EDAS compared to sample A-EDAS ( $+34 \%$ for $S_{\mathrm{BET}}$, $+31 \%$ for $V_{\text {Dubinin }}$ ), and almost identical pore size distributions. In this way, whatever the kind of aluminum precursor, doping the sample with EDAS allows obtaining a narrow pore size distribution centered on $4 \mathrm{~nm}$ with a maximal value of $10 \mathrm{~nm}$.

X-Ray diffraction patterns realized on calcined samples are shown in Figure 7.

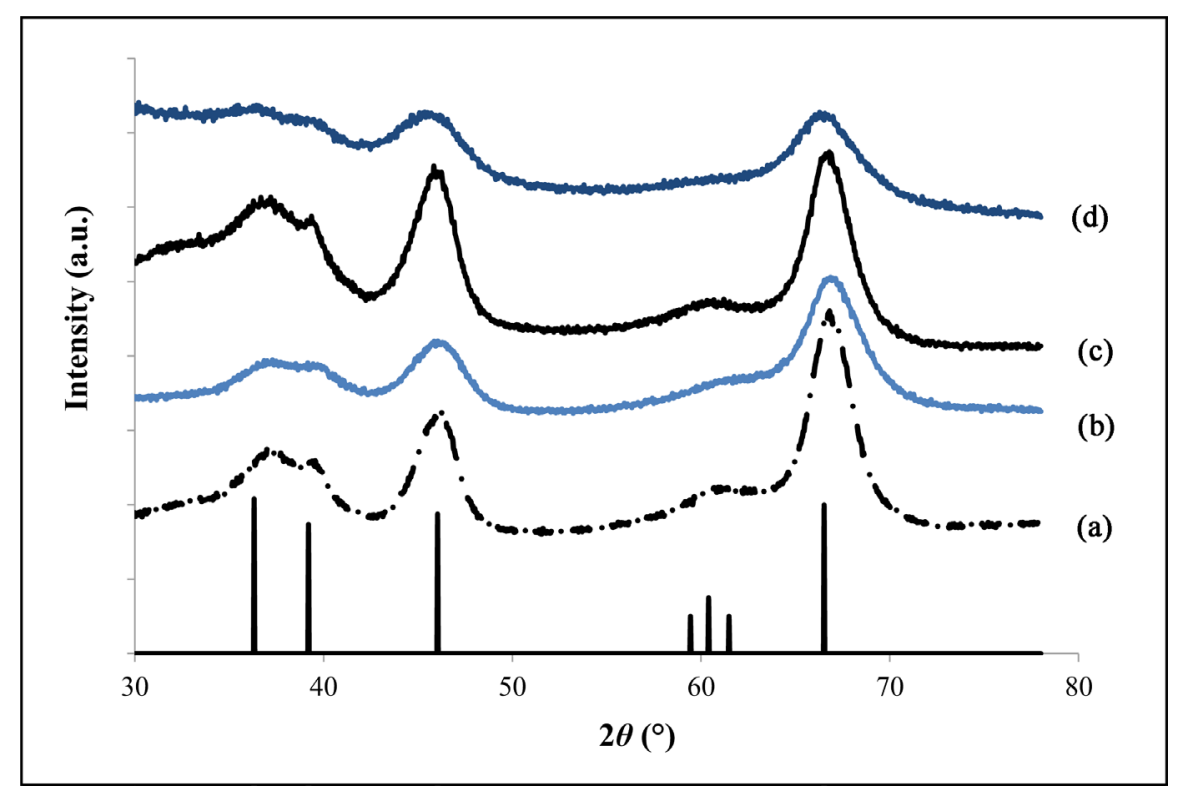

Figure 7. X-Ray patterns of $\gamma-\mathrm{Al}_{2} \mathrm{O}_{3}$ reference peaks and calcined samples; (a). A, (b). A-EDAS, (c). N, (d). N-EDAS. 
The alumina particle sizes, $d_{\mathrm{XRD}}$, are obtained using the Scherrer equation from the $\gamma-\mathrm{Al}_{2} \mathrm{O}_{3}$ peak located at $2 \theta=66.9^{\circ}$, which corresponds to the $\left(\begin{array}{lll}4 & 4 & 0\end{array}\right)$ planar direction (Table 2) [24]. It is observed that for both aluminum pre-cursors, the EDAS addition decreases the sizes of $\gamma-\mathrm{Al}_{2} \mathrm{O}_{3}$ particles (from 4.5 to 3.5 $\mathrm{nm}$ ). It is also observed that samples with similar compositions (i.e. samples $\mathrm{A}$ and $\mathrm{N}$, or samples A-EDAS and N-EDAS) present similar diffraction patterns.

The apparent density, $\rho$, of the samples (Table 2), i.e. the density including opening pores accessible to the gas according to IUPAC [29], are very close to the true density of calcined alumina gels, which is about $3.0 \mathrm{~g} / \mathrm{cm}^{3}$. The true density of calcined silica gels being about $2.2 \mathrm{~g} / \mathrm{cm}^{3}$ [17] [19], this could explain why the samples A-EDAS and N-EDAS present lower $\rho$ values compared to samples $\mathrm{A}$ and $\mathrm{N}$.

\section{Discussion}

\subsection{Influences of the Aluminum Precursor Nature on the Textural Properties of $\gamma-\mathrm{Al}_{2} \mathrm{O}_{3}$ Supports}

In the synthesis conditions used in this work, it seems that samples starting from two different aluminum precursors such as $\mathrm{Al}$ sec-butoxide (sample $\mathrm{A}$ ) and $\mathrm{Al}$ nitrate (sample $\mathrm{N}$ ) present equivalent thermal behavior (Figure 2), morphology (Figures 3-5), porosity (Figure 6) and crystallinity (Figure 7).

The textural and crystallographic similarities between samples $\mathrm{A}$ and $\mathrm{N}$ are attributed to the synthesis operating variables $(\mathrm{pH}=9.5$, Temperature of aging equal to $\left.85^{\circ} \mathrm{C}\right)$. Whereas the aqueous precipitation of aluminum nitrate is known to favor the formation of boehmite ( $\gamma$-AlOOH) [5] [9] [10], the hydrolysis of $\mathrm{Al}$ sec-butoxide is in the contrary known to lead to amorphous alumina hydroxide species $\left(\mathrm{Al}(\mathrm{OH})_{3}\right)$ [5]. However, in this case, sample A exhibits X-Ray peaks of well-crystallized $\gamma-\mathrm{Al}_{2} \mathrm{O}_{3}$ (Figure 7), which means that the synthesis conditions $\left(\mathrm{pH}, T_{\text {aging }}\right)$ used can successfully convert the amorphous alumina hydroxide species into crystalline boehmite.

\subsection{Modifications of the Properties of $\gamma-\mathrm{Al}_{2} \mathrm{O}_{3}$ Supports by the Use of a Functionalized Silicon Alkoxyde}

When EDAS is added during the synthesis of alumina samples (samples A-EDAS and N-EDAS), it is observed:

1) Though starting from different aluminum precursors, both samples A-EDAS and N-EDAS appear to be homogeneous (Figure 3 and Figure 4). This observation is particularly interesting for sample A-EDAS since the hydrolysis rates of silicon alkoxides are lower compared to aluminumal koxides. So without adequate preparation steps, it may lead to inhomogeneous materials [30]. Nevertheless, the formation of homogeneous aluminosilicate samples with different precursor types is shown by Sinko et al. [31]. In line with the present results, the authors showed that starting from a mixture of TEOS $+\mathrm{Al}\left(\mathrm{NO}_{3}\right)_{3}$ or TEOS + $\mathrm{Al}\left(\mathrm{OCH}\left(\mathrm{CH}_{3}\right)_{2}\right)_{3}$ reagents in water + ethanol media lead to homogeneous alu- 
minosilicate materials with similar textural and crystalline properties than pure alumina samples. Furthermore, another study showed that the cogelation of $\mathrm{Al}$ sec-butoxide and trimethoxysilane also allowed obtaining homogenous aluminosilicate supports [32].

So in this work, the formation of homogeneous aluminosilicate supports via the method A is possible thanks to the pre-hydrolysis step of EDAS before the Al sec-butoxide addition. Indeed, pre-hydrolysis steps are known to counterbalance the difference of alkoxide reactivity, thus allowing the formation of homogeneous cogelled materials [30].

The formation of homogenous supports via the method $\mathrm{N}$ is explained by oxolation/olation reactions between hydrolyzed $\mathrm{Si}-\mathrm{OH}$ groups from EDAS and alumina hydroxide complexes such as $\mathrm{Al}_{2}(\mathrm{OH})_{2}^{4+}$ or $\mathrm{Al}_{3}(\mathrm{OH})_{4}^{5+}$. It is assumed that these condensation reactions occur before the precipitation and lead to the formation of submicronic aggregates by cogelation since the sol remains transparent.

2) Comparing the properties of samples N-EDAS and A-EDAS reveals that starting from $\mathrm{Al}$ nitrate or $\mathrm{Al}$ sec-butoxide also leads to materials with similar properties. Indeed, despite the lower textural properties ( $V_{\text {Dubinin }}, V_{\mathrm{P}}$ and $S_{\mathrm{BET}}$, Table 2) of sample A-EDAS compared to sample N-EDAS, both samples exhibit similar thermal behaviour (Figure 2), morphology (Figures 3-5), porosity (Figure 6) and crystallinity (Figure 7).

3) Both EDAS modified alumina supports are characterized by a strong modification of their crystalline properties. Indeed, samples A-EDAS and N-EDAS show less defined alumina X-Ray peaks (Figure 7) compared to the pure alumina samples (samples A and N). Due to its methoxy groups, EDAS is classified as a high reactive silicon precursor [15] [16] [17] [18] [19]. This high reactivity could lead to an insertion of $\mathrm{Si}$ atoms inside the bulk alumina structure, thus modifying the $\gamma-\mathrm{Al}_{2} \mathrm{O}_{3}$ crystallinity.

4) EDAS strongly modifies the morphology of alumina samples. Indeed, for samples A-EDAS and N-EDAS, TEM observations (Figure 5) show the presence of spherical alumina particles, which could explain the very narrow pore size distribution obtained from the nitrogen adsorption-desorption isotherms (Figure 6). It is assumed that the high reactivity of the methoxy-groups in EDAS could lead to the quick formation of numerous nucleation points, which react by cogelation with aluminium precursor to form after calcination, spherical aluminosilicate particles [15] [16] [17] [18] [19] [30].

\section{Conclusions}

In this work, an easy experimental procedure for the synthesis of pure $\gamma-\mathrm{Al}_{2} \mathrm{O}_{3}$ supports is established by using aqueous sol-gel process. The alumina supports synthesized from $\mathrm{Al}$ nitrate used as precursor present higher porous volumes and specific surface areas compared to samples synthesized with $\mathrm{Al}$ sec-butoxide. Since nitrate salts are much easier to handle than alkoxides, it is advised to use 
$\mathrm{Al}\left(\mathrm{NO}_{3}\right)_{3}$ as aluminum source for the future synthesis of catalysts supported on alumina.

The aqueous sol-gel synthesis of homogeneous $\gamma-\mathrm{Al}_{2} \mathrm{O}_{3}$ supports modified with a functionalized silicon precursor (EDAS) is successfully realized with both aluminum sources. Hence, the synthesis of boehmite functionalized with a silicon precursor is performed thanks to the cogelation method, which could be an useful alternative to common grafting methods.

\section{Acknowledgements}

S. D. L. is grateful to the Belgian "Fonds de la Recherche Scientifique - Fonds National de la Recherche Scientifique (F.R.S.-F.N.R.S)" for her research associate position. The authorsacknowledge the Ministère de la Région Wallonne Direction Générale des Technologies, de la Recherche et de l'Energie (DG06), the Fonds de Recherche Fondamentale et Collective, PACODEL and ARES associations for financial supports.

\section{References}

[1] Brinker, C.J. and Scherer, G.W. (1990) Sol-Gel Science: The Physics and Chemistry of Sol-Gel Processing. Academic Press, San Diego.

[2] Sharma, P.K., Varadan, V.V. and Varadan, V.K. (2003) A Critical Role of pH in the Colloidal Synthesis and Phase Transformation of Nano Size $\alpha-\mathrm{Al}_{2} \mathrm{O}_{3}$ with High Surface Area. Journal of the European Ceramic Society, 23, 659-666. https://doi.org/10.1016/s0955-2219(02)00191-7

[3] Zelinski, B.J.J. and Uhlmann, D.R. (1984) Gel Technology in Ceramics. Journal of Physics and Chemistry of Solids, 45, 1069-1090. https://doi.org/10.1016/0022-3697(84)90049-0

[4] Elnahrawy, A. and Ali, A. (2014) Influence of Reaction Conditions on Sol-Gel Process Producing $\mathrm{SiO}_{2}$ and $\mathrm{SiO}_{2}-\mathrm{P}_{2} \mathrm{O}_{5}$ Gel and Glass. New Journal of Glass and Ceramics, 4, 42-47. https://doi.org/10.4236/njgc.2014.42006

[5] Livage, J. (1998) Sol-Gel Synthesis of Heterogeneous Catalysts from aqueous Solutions. Catalysis Today, 41, 3-19. https://doi.org/10.1016/S0920-5861(98)00034-0

[6] Rajaeiyan, A. and Bagheri-Mohagheghi, M.M. (2013) Comparison of Sol-Gel and Co-Precipitation Methods on the Structural Properties and Phase Transformation of $\gamma$ and $\alpha-\mathrm{Al}_{2} \mathrm{O}_{3}$ Nanoparticles. Advanced Manufacturing,1, 176-182. https://doi.org/10.1007/s40436-013-0018-1

[7] Panias, D., Asimidis, P. and Paspaliaris, I. (2001) Solubility of Boehmite in Concentrated Sodium Hydroxide Solutions: Model Development and Assessment. Hydrometallurgy, 59, 15-29. https://doi.org/10.1016/S0304-386X(00)00146-8

[8] Santos, P.S., Santos, H.S. and Toledo, S.P. (2000) Standard Transition Aluminas. Electron Microscopy Studies. Materials Research, (2000), 3, 104-114. https://doi.org/10.1590/s1516-14392000000400003

[9] Okada, K., Nagashima, T., Kameshima, Y., Yasumori, A. and Tsukada, T. (2002) Relationship between Formation Conditions, Properties, and Crystallite Size of Boehmite. Journal of Colloid and Interface Science, 253, 308-314. https://doi.org/10.1006/jcis.2002.8535

[10] Lee, H.W., Park, B.K., Tian, M.Y. and Lee, J.M. (2006) Relationship between Prop- 
erties of Pseudo-Boehmite and Its Synthetic Conditions. Journal of Industrial and Engineering Chemistry, 12, 295-300.

[11] Mirjalili, F., Chuah, L., Mohamad, H. and Fakhru, A. (2011) Effect of Stirring Time on Synthesized of Ultra Fine $\alpha-\mathrm{Al}_{2} \mathrm{O}_{3}$ Powder by a Simple Sol-Gel Process. Journal of Ceramic Processing Research, 12, 738-741.

[12] Akhlaghian, F., Tow, J., Mohajeri, A. and Zamaniyan, A. (2010) Comparison of SolGel Methods for Wash Coating Metallic Substrates. Chemistry Chemical Engineering, 17, 191-197.

[13] Steen, E., Claeys, M. and Callanan, L.H. (2004) Recent Advances in the Science and Technology of Zeolites and Related Materials. Elsevier, Cape Town.

[14] Lambert, S., Sacco, L., Ferauche, F., Heinrichs, B., Noels, A. and Pirard, J.P. (2004) Synthesis of $\mathrm{SiO}_{2}$ Xerogels and $\mathrm{Pd} / \mathrm{SiO}_{2}$ Cogelled Xerogel Catalysts from Silylated Acetylacetonate Ligand. Journal of Non-Crystalline Solids, 343, 109-120. https://doi.org/10.1016/j.jnoncrysol.2004.07.049

[15] Alié, C., Lambert, S., Heinrichs, B. and Pirard, J.P. (2003) Nucleation Phenomenon in Silica Xerogels and $\mathrm{Pd} / \mathrm{SiO}_{2}, \mathrm{Ag} / \mathrm{SiO}_{2}, \mathrm{Cu} / \mathrm{SiO}_{2}$ Cogelled Catalysts. Journal of SolGel Science and Technology, 26, 827-830. https://doi.org/10.1023/A:1020799616387

[16] Lambert, S., Cellier, C., Ferauche, F., Gaigneaux, E.M. and Heinrichs, B. (2007) On the Structure-Sensitivity of 2-Butanol Dehydrogenation over $\mathrm{Cu} / \mathrm{SiO}_{2}$ Cogelled Xerogel Catalysts. Catalysis Communications, 8, 2032-2036.

https://doi.org/10.1016/j.catcom.2007.04.004

[17] Pirard, S.L., Mahy, J.G., Pirard, J.P., Heinrichs, B., Raskinet, L. and Lambert, S.D. (2015) Development by the Sol-Gel Process of Highly Dispersed $\mathrm{Ni}-\mathrm{Cu} / \mathrm{SiO}_{2}$ Xerogel Catalysts for Selective 1, 2-Dichloroethane Hydrodechlorination into Ethylene. Microporous and Mesoporous Materials, 209, 197-207. https://doi.org/10.1016/j.micromeso.2014.08.015

[18] Alié, C., Ferauche, F., Léonard, A., Lambert, S., Tcherkassova, N., Heinrichs, B., Crine, M., Marchot, P., Loukine, E. and Pirard, J.P. (2006) Pd-Ag/SiO 2 Xerogel Catalyst Forming by Impregnation on Alumina Foams. Chemical Engineering Journal, 117, 13-22. https://doi.org/10.1016/j.cej.2005.11.011

[19] Lambert, S., Gommes, C., Alié, C., Tcherkassova, N., Pirard, J.P. and Heinrichs, B. (2005) Formation and Structural Characteristics of $\mathrm{Pd}-\mathrm{Ag} / \mathrm{SiO}{ }_{2}$ and $\mathrm{Pd}-\mathrm{Cu} / \mathrm{SiO}_{2}$ Catalysts Synthesized by Cogelation. Journal of Non-Crystalline Solids, 351, 38393853. https://doi.org/10.1016/j.jnoncrysol.2005.10.019

[20] Mahy, J.G., Tasseroul, L., Zubiaur, A., Geens, J., Brisbois, M., Herlitschke, M., Hermann, R., Heinrichs, B. and Lambert, S.D. (2014) Highly Dispersed Iron Xerogel Catalysts for $p$-Nitrophenol Degradation by Photo-Fenton Effects. Microporous and Mesoporous Materials, 197, 164-173.

https://doi.org/10.1016/j.micromeso.2014.06.009

[21] Hardin, J.L., Oyler, N.A., Steinle, E.D. and Meints, G.A. (2010) Spectroscopic Analysis of Interactions between Alkylated Silanes and Alumina Nanoporous Membranes. Journal of Colloid and Interface Science, 342, 614-619. https://doi.org/10.1016/j.jcis.2009.10.083

[22] Sripathi, V.G.P., Mojet, B.L., Nijmeijer, A. and Benes, N.E. (2013) Vapor Phase versus Liquid Phase Grafting of Meso-Porous Alumina. Microporous Mesoporous Materials, 172, 1-6. https://doi.org/10.1016/j.micromeso.2013.01.013

[23] Yang, S., Yuan, P., He, H., Qin, Z., Zhou, Q., Zhu, J. and Liu, D. (2012) Effect of Reaction Temperature on Grafting of $\gamma$-Aminopropyl Triethoxysilane (APTES) onto Kaolinite. Applied Clay Science, 62-63, 8-14. 
https://doi.org/10.1016/j.clay.2012.04.006

[24] Bergeret, G. and Gallezot, P. (1997) Particle Size and Dispersion Measurements. In: Ertl, G., Knözinger, H. and Weitkamp, J., Eds., Handbook of Heterogeneous Catalysis, Wiley-VCH, Weinheim, 439-491.

[25] Bi, S., Wang, C., Cao, Q. and Zhang, C. (2004) Studies on the Mechanism of Hydrolysis and Polymerization of Aluminum Salts in Aqueous Solution: Correlations between the 'Core-Links' Model and 'Cage-Like' Keggin-Al13 Model. Coordination Chemistry Reviews, 248, 441-455. https://doi.org/10.1016/j.ccr.2003.11.001

[26] Lambert, S., Polard, J.F., Pirard, J.P. and Heinrichs, B. (2004) Improvement of Metal Dispersion in $\mathrm{Pd} / \mathrm{SiO}_{2}$ Cogelled Xerogel Catalysts for 1, 2-Dichloroethane Hydridechlorination. Applied Catalysis B: Environmental, 50, 127-140. https://doi.org/10.1016/j.apcatb.2004.01.015

[27] Raybaud, P., Digne, M., Sautet, P., Euzen, P. and Toulhoat, H. (2004) Use of DFT to Achieve a Rational Understanding of Acid-Basic Properties of Gamma-Alumina Surfaces. Journal of Catalysis, 226, 54-68. https://doi.org/10.1016/j.jcat.2004.04.020

[28] Alphonse, P. and Courty, M. (2005) Structure and Thermal Behavior of Nanocrystalline Boehmite. Thermochimica Acta, 425, 75-89.

https://doi.org/10.1016/j.tca.2004.06.009

[29] Rouquérol, J., Avnir, D., Fairbridge, C.W., Everett, D.H., Pernicone, N., Ramsay, J.D., Sing, K. and Unger, K.K. (1994) Recommendations for the Characterization of Porous Solids. Pure and Applied Chemistry, 66, 1739-1758.

https://doi.org/10.1351/pac199466081739

[30] Reale, E., Leyva, A., Corma, A., Martínez, C., García, H. and Rey, F. (2005) A Fluoride-Catalyzed Sol-Gel Route to Catalytically Active Non-Ordered Mesoporous Silica Materials in the Absence of Surfactants. Journal of Materials Chemistry, 15, 1742-1754. https://doi.org/10.1039/b415066j

[31] Sinko, K., Hüsing, N., Goerigk, G. and Peterlik, H. (2008) Nanostructure of GelDerived Aluminosilicate Materials. Langmuir, 24, 949-956. https://doi.org/10.1021/la702525x

[32] Ma, K., Mendoza, C., Hanson, M., Werner-Zwanziger, U., Zwanziger, J. and Wiesner, U. (2015) Control of Ultrasmall Sub-10 Nm Ligand-Functionalized Fluorescent Core-Shell Silica Nanoparticle Growth in Water. Chemistry of Materials, 27, 4119-4133. https://doi.org/10.1021/acs.chemmater.5b01222 
Submit or recommend next manuscript to SCIRP and we will provide best service for you:

Accepting pre-submission inquiries through Email, Facebook, LinkedIn, Twitter, etc. A wide selection of journals (inclusive of 9 subjects, more than 200 journals)

Providing 24-hour high-quality service

User-friendly online submission system

Fair and swift peer-review system

Efficient typesetting and proofreading procedure

Display of the result of downloads and visits, as well as the number of cited articles Maximum dissemination of your research work

Submit your manuscript at: http://papersubmission.scirp.org/

Or contact ampc@scirp.org 